\title{
CONDITIONS OF IMPLEMENTATION OF AN INDUCTIVE LEARNING SEQUENCE ABOUT THE PERIODIC TABLE IN HIGH SCHOOL CHEMISTRY
}

\author{
Louis Trudel ${ }^{1} \&$ Abdeljalil Métioui ${ }^{2}$ \\ ${ }^{1}$ Université d'Ottawa, Faculté d'éducation, 145, rue J ean-J acques-Lussier, Ottawa (Ontario), \\ K1N 6N5, Canada \\ 2Université du Québec à Montréal, Case postal 8888, succursale Centre-ville, Montréal(Québec) H3C \\ 3P8
}

\begin{abstract}
In chemistry education, understanding the structure and role of the Periodic Table has been linked to subsequent learning of key concepts such as the properties of chemical elements. However, the way teachers introduce the Periodic Table to high school students is mostly traditional, students learning to use it to predict properties of elements according to given rules (Ben-Zvi \& Grenut, 2007). Such a way to proceed does not allow students to engage in authentic science activities. Thus our research pursues two main objectives. The first one is to conceive a learning sequence to engage students in activities where they have to propose their hypotheses and verify them against data. The second one is to study the condition of implementation of this learning sequence in high school chemistry course. The experimentation took place with 14 adult learners who followed a high school chemistry course in two successive periods of two hours each in an adult learning center. To study the implementation of the learning sequence, the main researcher held a research diary where he recorded his observations on the sequence of events. In it, healso wrote his reflections about the observed events and established links between his observations and the theoretical framework of the present research (Altrichter \& Holly, 2005). Our results point out that the sequence engages students in developing the classifications as well as find arguments to test them as they discuss their ideas in small groups and later expose them during classroom discussion. Wealso discuss conditions of implementation, such as the importance of providing a way to register all the contributions of each team to help sharing and examining the various hypotheses. One key aspect concerns the ability of the teacher to find the proper balance between supporting students' process of categorization while not interfering with it. As a conclusion, we discuss the advantages and the limits of the research and made suggestions for future research.
\end{abstract}

\section{Introduction}

In chemistry education, understanding the structure and role of the Periodic Table has been linked to subsequent learning of key concepts such as the properties of chemical elements and the chemical bond. With respect to the historical development of the periodic table, science historians do not agree on the principal mechanism responsible for the discovery of the periodicity property of the elements. Was it discovered by induction from observed properties of elements or was it deduced from theoretical principles of the atomic theory (Brito Rodriguez, Niaz, 2005)? With respect to the latter, one must note that scientists made most of the discoveries that led to atomic theory after the development of the periodic table by Mendeleev. Therefore, one must conclude that the elaboration of the periodic table was 
not due to a deduction from first principles of the atomic theory (Scerri, 2011). However, some principles of atomic theory were already in place. For example, the law of multiple proportions, which states that atoms combine in whole number ratios, had already been proposed by Dalton. Avogadro had proposed his hypothesis for determining the atomic weight of the elements. Based on these results, Cannizzaro had proposed a method to distinguish between atoms and molecules by specifying the concept of equivalent mass. From these principles, several others proposed different versions of the periodic table. Hence, Newlands proposed the law of octaves that bears its name based on the fact that each row of the periodic table contains eight elements. Newlands also explained the formation of the different chemical compounds by using the notion of valence. More specifically, Newlands used the notion of triads to predict the properties of elements based on the ones already known of its neighbours, a process that will be used with success by Mendeleev. Furthermore, historians agree that Mendeleev's vast knowledge of the properties of elements and chemical compounds allows him to propose a more achieved version of the Periodic Table than his competitors (Scerri, 2011).

Since the historical evidence gathered so far points out that the elaboration of the periodic table was mainly due to inductive processes, it remains to specify induction about what? In this regard, the development of the periodic table requires that two important aspects are taken into account. First, the principle of periodicity states that the physical properties repeat themselves at regular intervals called periods. Second, the chemical properties of elements are similar between groups of elements (as in columns or families). Specifically, the concept of chemical valence allows the determination of the atomic mass of an element from the compounds it forms with other elements (Scerri, 2011). These two principles allow us to distinguish between elements and compounds. This macroscopic distinction leads one to associate the notion of element to the atom, and the notion of compounds to the molecule (Brito Rodriguez, Niaz, 2005; Martinand, 1986). Indeed, the new method of determination of atomic masses presented in Karlsruhe Congress in 1860 by the chemist Cannizarro was based on the Avogadro's hypothesis and the concept of atomic valence (Krebs, 2006). Following this breakthrough, not less than six participants to the conference proposed, in the ten years following the event, various versions of a periodical table (Scerri, 2011).

Other physical properties were also important to reveal the principles of periodicity and family of elements. These physical properties were the atomic number, electrical conductivity, thermal conductivity, density, reflection of light (since metals are shiny while non-metals are dull), the state of matter (solid, liquid, gas), the boiling point, the melting point. Let us note that, compared to room temperature, the melting and boiling points of an element determined its state of matter at this temperature. Also, these properties must be specific, that is to say that a set of them can be used to distinguish between elements (Martinand, 1986). It is also known that several physical properties of elements, such as boiling points or atomic volumes, may vary with the increase of the atomic mass. Therefore, 
the choice of chemical and physical properties is very important to facilitate the induction process (Scerri, 2011).

With respect to chemical properties, the notion of valence was very important not only because it contributed to the determination of atomic masses but also because it was used to group items in columns. An example of this is the formation of oxides and salts (Ensley, 2011). Thus, the way an element can combine with other elements forming various compounds played a leading role in the identification of the families of elements (AlderseyWilliams, 2011).

Moreover, one of the key concept leading to organization of the elements in a periodic table is the result of a play between various properties. First, one must play with chemical properties to arrange the elements in columns or families. Second, one must play with physical properties to arrange elements along periods. Finally, one must identify the right place of an element at the intersection of a column and a row. Hence, the task of organizing elements in a periodic table could be seen as similar to different plays with a deck of cards. Indeed, a legend suggests that Mendeleev was a famous card player. According of this legend, the most satisfying version of the periodic table would have appeared to him in a dream after years of effort (Baylor, 2001; Barrett, 2001). Furthermore, it is well known that Mendeleev had his first idea of a periodic table while he was trying to organize the presentation of elements in a chemistry book. This fact tells a lot about the pedagogical value of the periodic table as a teaching tool (Gordin, 2005). Thus, with the periodic table, teachers, and their students, dispose of a tool that shows the bulk of physical and chemical properties in a condensed and easily accessible form. Indeed, the importance of the periodicity principle allow a clear presentation of chemical principles associated with elements, communicating an order where previous textbooks had focused on an encyclopedic presentation of the properties of the elements.

However, teachers still introduced the Periodic Table to high school students in a traditional way. Indeed, students learning to use it, in the form presented, to predict properties of elements according to given rules (Ben-Zvi \& Grenut, 2007). Such a way to proceed does not allow students to engage in authentic science activities. Thus our research pursues two main objectives. The first one is to conceive an inductive learning sequence to engage students in activities where they have to propose their hypotheses and verify them against data. The second one is to study the condition of implementation of this learning sequence in high school chemistry course.

\section{Conception of the learning sequence}

Based on our historical reconstruction of the development of the Periodic Table, our inductive learning sequence is composed of five stages (Monk \& Osborne, 1997; Brito, Rodriguez \& Niaz, 2005; J oyce \&Weil, 2004). These stages are described as followed:

1) The teacher gives a short introduction to his students to review the basic notions of elements and their properties and the use of classification in science. 
2) The teacher groups his students into small teams and give them a deck of cards. Each deck contains some information about each element (name and symbol of the element) and blanks to be completed. With respect to the blanks, the students had to choose the properties they want to use for classifying elements and write the name of the property under the blank. Once the students have chosen these properties, they wrote, in the corresponding blank, its numerical value if the property is quantitative or a short description if the proprety is qualitative.

3) In small teams, students discuss their classification of elements according to properties written on their cards.

4) In whole class, teacher animates a discussion where students compared their classifications obtained in precedent steps.

5) The teacher presents to his class a film on chemical families where his students compare their results with key features of the Periodic Table of elements.

The learning objectives of the sequence consist of: 1) gaining knowledge of the properties of the chemical elements; 2) discovering the notion of family of elements; 3) developing scientific basic skills. More precisely, students should be able, at the end of the sequence, to master the basic process of inductive thinking. The inductive thinking process proposed here comprises the following stages. First, students identify the common points between the chemical elements to formulate rules and laws. Based on these rules, they formulate hypotheses that they try to sustain or disregard by bringing up arguments for or against them. Once sufficient evidence has been brought forward, these hypothesis may lead to the formulation of theories. To design his sequence, the teacher starts by choosing the contents to be taught, which is represented by key concepts of chemical elements. Then, he elaborates the activities to allow the attainment of the objectives of the course. These activities must be part of the three major inductive strategies defined by Taba (J oyce \&Weil, 2004: Taba, 1971): 1) the formation of concepts; 2) the interpretation of data ; and 3) the resolution of problems.

Learning occurs according to the "natural" sequence of presentation of the inductive strategies 1), 2), 3), as described above. Every strategy, using appropriate teacher's questioning, leads the students to perform some mental operations. The teacher must be sure that the majority of the students master each strategy before going to the next. The role of the teacher is to guide students by encouragements, feedback, questions, advice and providing adequate resources. These resources should be familiar to the students and support the inductive process.

\subsection{Choice and organization of contents}

The first stage in the planning of the learning sequence is to identify key concepts, those who are prerequisite to the learning objectives and those who must be learned at the end of the process. The prerequisite concepts are: 1 ) differentiation between elements and compounds, between pure and mixed substances (Martinand, 1986); 2) the characteristic properties of pure substances: mass, volume, atomic number, melting points and boiling points, electrical 
and thermal conductivity, electronic structure, etc.; 3) the notion of chemical properties: chemical reactivity, etc. ; 4) the notion of physical properties: shine, mat, conductor of electricity, conductor of heat, physical state (solid, liquid, gas), hard or soft, malleable. The target concept is the notion of family of elements.

\subsection{Choice of activities and strategic planning}

The second stage consists of choosing the activities that will allow the implementation of the three following strategies: formation of concepts, interpretation of data, problem-solving.

\subsubsection{Concepts formation}

With appropriate questioning, the teacher writes, in the left part of the chalkboard, a list of elements proposed by students and, in the right part, a list of the properties suggested by the students. While doing so, the teacher leads students by questions to make links between an element and its characteristic properties. Throughout this process, students should be made aware that each element possesses a set of characteristic properties and, reciprocally, a group of elements can share one or several common characteristics. Then, the teacher initiates a whole classroom discussion on the interest of classification in sciences. When he feels that the students understand and agree to the proposed activities, he communicates his instructions to start the first activity.

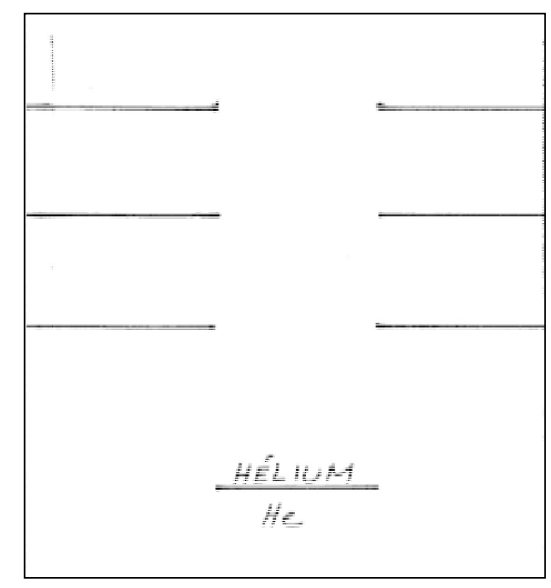

Figure 1. Card where students fill in the properties of the elements (here Helium)

First, the class is divided into small groups. Every group receives a list of elements and their properties as well as a deck of small cards where is written the symbol of every element. These cards also contains several vingin lines on which pupils can note some of the properties they have chosen (fig. 1). The students also receive a table of the electronic configuration of the first twenty elements that they have to fill by using the information provided in the list (see fig. 2). 
It is also possible for them to consult an encyclopedia on the properties of chemical substances. The teacher passes from group to group to support the learning of his pupils and gives them encouragement, advice or additional information.

\subsubsection{Interpretation of data}

Back in plenary, each team presents its classification to the class as well as the reasons that motivated their choices. A discussion follows between pupils, animated by the teacher, to help them elaborate on the reasons of this or that classification, or on the possibility to merge categories and subdivide others. At this stage, the teacher tries, by appropriate incentive questions, to lead the class to generalize the results obtained, to enunciate hypotheses on links discovered between the elements of the same group.

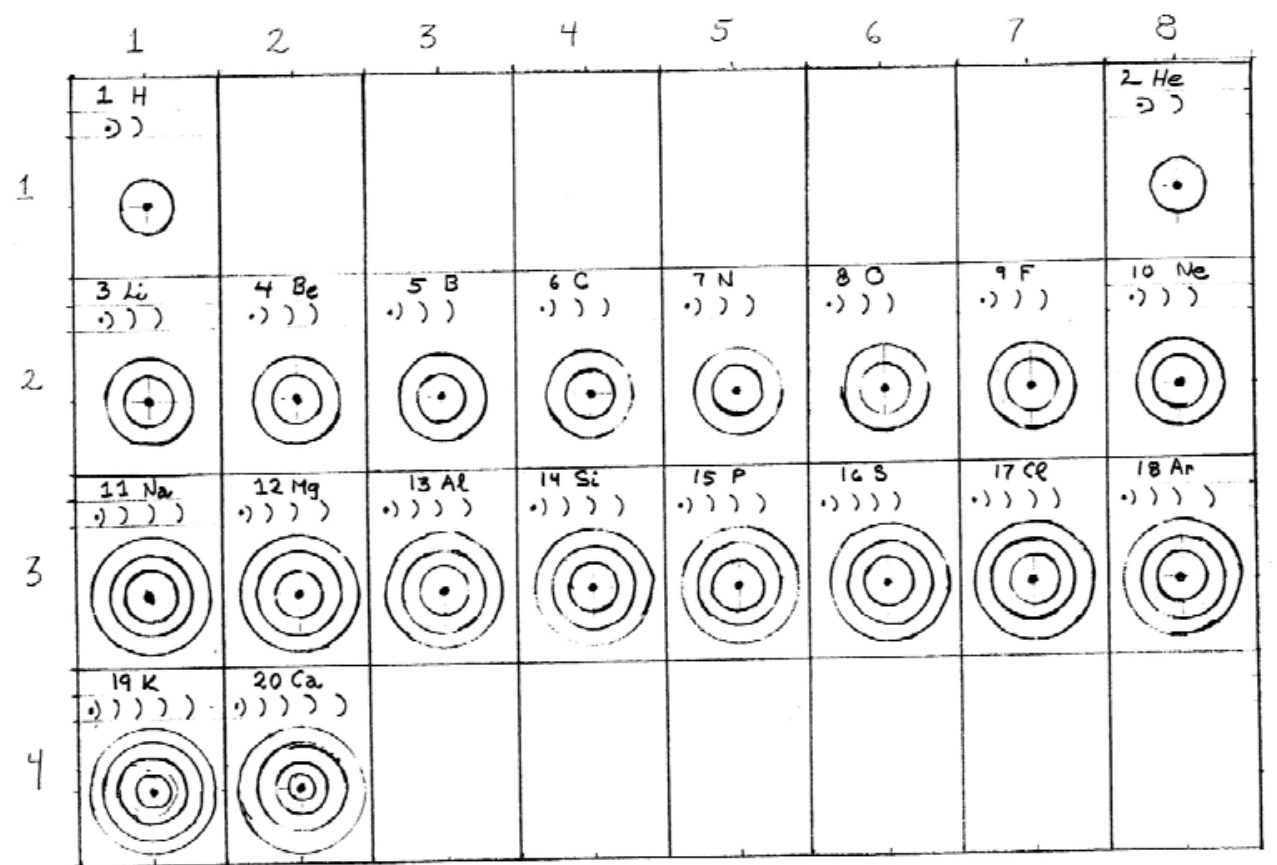

Figure 2. Table of electronic configuration of the first twenty elements

\subsubsection{Problem solving}

At the end of the process, there will be the presentation of a film concerning the chemical families. Then, the teacher will begin a discussion of the classifications made by the pupils as well as the hypotheses that follow from them and those introduced in the film. To stimulate the discussion, the teacher asks his pupils the following questions: In which way, the hypotheses proposed by pupils and the scientific principles exposed in the film are similar? In which way do they differ? In which way, the periodic table of elements can serve us in the study of chemical properties? 


\subsection{Resources}

As specified before, the resources at students disposal consisted of a list of elements and their properties, a set of cards carrying the symbol of every element and spaces to be filled with chosen properties, a table of electronic configuration of the first twenty elements which the students have to fill in, the Encyclopedia "Time Life" on matter, and a film on chemical families.

\subsection{Roles of the teacher}

The teacher introduces the situation of departure. He presents to his pupils the activities in a clear and invigorating way. He also supports his pupils, mainly during the first strategy, at emotional and cognitive levels. He does so by giving them encouragement, information, or even suggestions. In this exceptional case, he has to make sure he does not hinder their step. He plays the role of an animator during the second stage generally in plenary discussion. He uses then the suggestions of his students to build the course. He leads the pupils to react to the statements of others. He makes sure that the majority of the pupils master well a stage before going to the next.

\subsection{Social system}

The teacher supervises the interactions in an atmosphere of cooperation. The teacher must make sure that the interventions of the pupils are welcome and that all the participants are treated equally, including himself. As time goes, the teacher must leave more and more place to the pupil as this one acquires more autonomy.

\section{Methodology}

The experimentation took place in an adult learning center in two successive periods of two hours each. The subjects of the research were 14 adult learners, from twenty to fifty years old, who followed a high school chemistry course. The mission of this center is to make every effort to ensure that the adult learner develops skills, behaviors and attitudes that will enable it to succeed in his studies and enter the job market. To achieve his objectives, the center offers personalized monitoring of the student in connection with their learning profile, different teaching and learning styles, coaching promoting educational success. In this center, students are adults of various ages, making a return to school. The teaching model used promotes mainly individualized learning, students following their learning path.

The teacher handles the supervision of some students whom he tutors. In this respect, he prescribes activities or a specific learning path according to courses selected by the student. The programs consist of individual books with experiments to do according to the level of the student and the availability of resources in laboratories. Students' guides include booklets in which are written questions to answer by students and readings in compulsory textbooks available to students according to his level. Despite the support and resources available to them and their higher sense of responsibility, students are taking much longer than expected to complete their modules and some accumulate absences and delays. To alleviate these 
difficulties, the school director established a mixed pedagogical formula. This formula consists in forming small groups of students that follow a similar path led by a teacher specialist of the discipline. The research presented here had been conducted in one of these groups.

To study the implementation of the learning sequence, the main researcher held a diary where he recorded his observations on the sequence of events. His diary also contains his reflections about the observed events, and links between his observations and the theoretical framework of the present research (Altrichter \& Holly, 2005). It is to note that the main researcher was also the teacher. The diary respectively served two functions. The first function was to document the research process in trying to determine the conditions for implementation of the proposed approach in the targeted areas. The second function was to document the pedagogical process when the researcher/teacher used as it a reflective tool in planning his teaching approach. These two functions are interdependent for two reasons. First, the indications of the researcher of the diary serve to adjust the approach chosen. Conversely, the notes taken in the professional diary will assess the effects of these adjustments to the educational process (Moxley, 2007). Whatever its function, the diary is the external memory of the researcher/ teacher. The dairy allows him to understand better, takes a step back from his design, organize his ideas, etc. To do this, the dairy contains written material of various quality and types including the following major elements: 1) the data collected during the observations of the environment involved in the discussions with students, readings before, during or after teaching; 2) information on the context in which these data were collected; 3) reflections and interpretations of the researcher/ teacher on the data collected; 4) ideas or plans for future research steps (Altrichter \& Holly, 2005; Moon, 2006).

\section{Presentation of results and interpretation}

According to the diary, the activities of the sequence unfolded as follow. The formation of concepts takes place in three stages: 1) listing and production of lists; 2) regrouping of categories; 3) labeling, categorization.

\subsection{Enumeration and production of lists:}

The teacher conceived and asked questions to have students express their ideas about key concepts of the periodic properties of elements.

- 1 st incentive question: Can you name me the elements that you know?

The teacher made a list of answers provided by students on the blackboard: gold, silver, copper, zinc, hydrogen, oxygen, helium, water (?), calcium, potassium, aluminium, carbon.

- $2^{\text {nd }}$ incentive question: What are the properties of pure substances that you saw up to now? 
The teacher registered students' answers on the right part of the blackboard. Some examples of students answers follows: electrical conductivity, thermal conductivity, temperature of fusion, temperature of boiling, mass, physical state (solid, liquid and gas), malleability, brightness, chemical reactivity, hardness, electronic structure.

- $\quad 3^{\text {rd }}$ incentive question: Do you think that a set of properties determines a specific substance? Answers: yes or no according to the pupils.

- $4^{\text {th }}$ incentive question: What substance is liquid at room temperature and freezes at zero Celsius? Answer: everybody found it, it is the water.

- $5^{\text {th }}$ incentive question: What substance is a gas at room temperature and blows up in the presence of a flame? Answer: some students had it, it is the hydrogen.

- $6^{\text {th }}$ incentive question: Could you regroup elements according to their common characteristics? Some people then suggested that the gold, the money, the copper, the tin, were all metals.

From observations in the classroom, students very much liked these conundrums, and it appeared to motivate them to engage in the activity. At this stage, as the teacher, I did not want to go forward with the choice of categories in order not to restrain their choices unduly. I gave them instructions for the pursuit of the activities: "You are going to accomplish now an activity that gets you closer to the real work of the scientists. You are going to try to regroup elements according to common characteristics that you will have determined as the most important. Also find a name for every formed group of properties and point out the reasons for your choice." I distributed them the list of elements and their properties as well as a set of cards where were written on each one the symbol of an element and where there was enough space to write down the chosen properties of the element.

Several students did not understand what they had to do. I, therefore, wrote instructions on the blackboard. At this moment, four students leave the course for various reasons: appointment with the dentist, examination to be completed, etc. Consequently, a dozen students participate in the activity, the majority of them with enthusiasm, some with difficulty. This part took place during about lh30; that is until the end of the course. I asked them to write the categories that they had found on a sheet of paper in order not to lose the fruit of their work. I thought that the presence of the set of cards did not encourage them to note their step. In that respect, the fact to have to write properties they had chosen on cards made them lose a lot of time.

During this stage, I circulated from a group to the other one to encourage, give them information and to suggest them approaches. For example, I suggested to make categories that regroups elements that possess several common points. Other suggestions concern students' categorizations where he suggests making make more subdivisions in their groupings if he saw that these were too broad. At the opposite, I even suggested to merge several groupings if these contained too few elements. During the evening, I thought to a follow-up activity in a most beneficial way. I knew that a significant number of pupils had not been able to attend the activity and that they would be there the following day. It was 
necessary for me to be sure that they could participate to a certain extent. Besides, the course being speeded up, I had a very tight schedule of due dates to respect. Every day, I had to pass across some objectives. Besides, two days later, another teacher had to take care of the class: we shared task together to give a lesson.

However, I did not want to penalize the students who had followed activity. I decided, therefore, to go on with the activity by adopting a compromise. In the first hour, we would discuss in plenary the classifications of the students to identify its key points, to suggest causal relations and to enunciate hypotheses. In the second hour, we would make links between results got by the pupils and those of the scientists, i.e. the notion of family and the periodic table of elements. I then asked myself the following question: Could I get the concepts wanted from classifications got by the pupils? Was it possible in following this method to construct the periodic table? At my surprise, it was indeed possible and even logical: I transcribed, therefore, the result of this step on transparencies that could be viewed with an overhead projector. This activity would challenge the students, as they could compare their classifications with the teacher's one, and it would motivate them since I would use their classifications in my lecture.

\subsection{Discussion of the classifications obtained by students}

This activity took place the next day and lasted about an hour. I asked each team to give me the names of the classifications they made as well as the elements that were associated with each classification. Here are the results:

1st team classification: Bright - inert chemically- breakable- abundant element on earth malleable- poison - radioactive

\section{$2^{\text {nd }}$ team:}

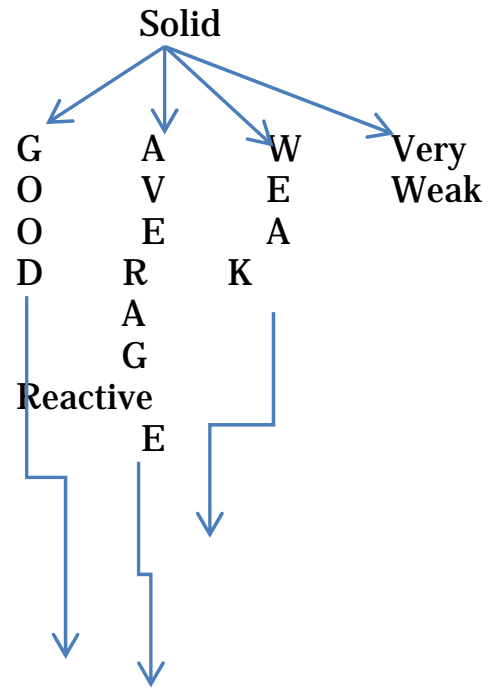

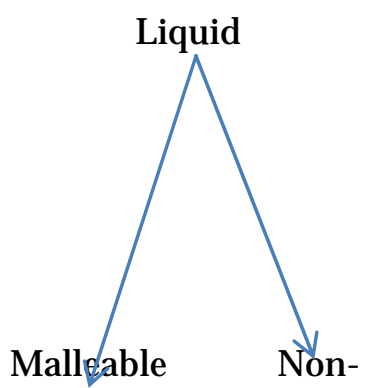

malleable

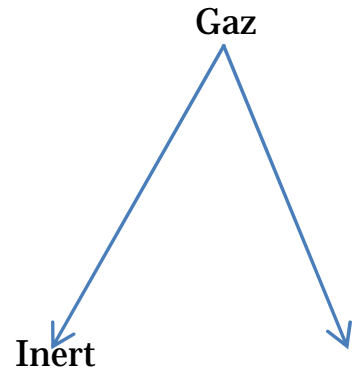

Inert

列


$3^{\text {rd }}$ team: The elements are classified according to the number of electrons on their last layer:

$\begin{array}{llllllll}1 & 2 & 3 & 4 & 5 & 6 & 7 & 8\end{array}$

$4^{\text {th }}$ team:

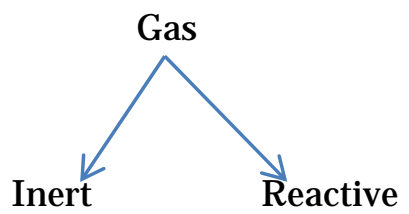

Disinfectant

After writing the classification of each team on the blackboard, I asked the class if they saw another way to regroup the elements. Often spontaneous students' interventions put us on track. Here, as examples, we present in the following the comments given by other students in the class. For example, with respect to the classification of the first team, one student suggested that malleable and shiny should be put together because the malleable elements are also brilliant: they are usually metals. Another student suggested that poison and radiation are to be put together because radioactive elements are also poisons.

With respect to the classification of the second team, the student who did the groupings justified them by saying that all good electric conductors are also good thermal conductors. Another student criticized the category of non-malleable liquid saying that all liquids were malleable, and, therefore, this category contains no elements. With respect to the classification of the third team, students who have achieved this classification defended it by saying that elements with the same number of valence electrons showed common properties. With respect to the classification of the fourth team, the category "disinfectant" containing mainly gas, a student asked if all disinfectants were also gaseous elements.

At this point, I asked the students the following question: "Do you want to see the classification I have found?" I showed them then the classification to which I arrived in systematizing their ones the previous evening: 

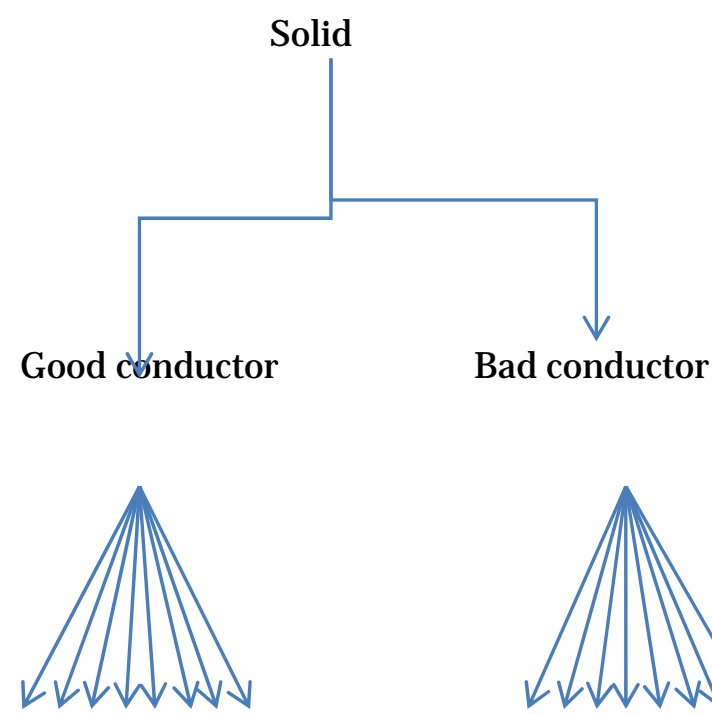

12345678

5678
Liquid

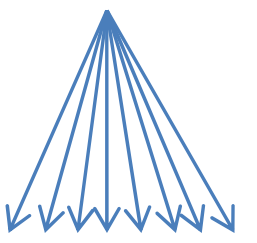

12345678
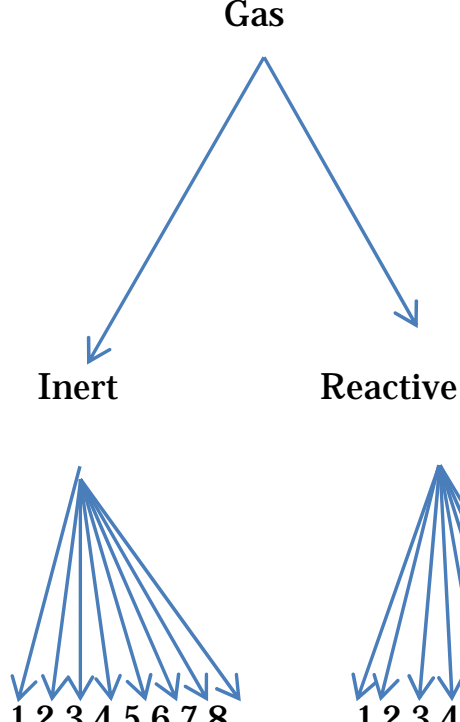

12345678

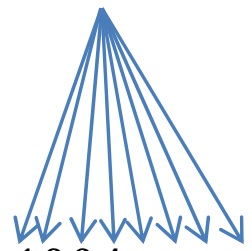

1234

The number of liquid elements was too small to divide into subgroups.

This classification was interesting because it showed the properties that go together:

- The solids that are good conductors are also shiny and malleable. They are called metals.

- The solids that are poor conductors are dull and brittle. They are called non-metals.

- Items that are in gaseous state form a family together known as the inert gasses.

- The chemically reactive gasses could be subdivided into two subgroups: the gas air component (oxygen, hydrogen, nitrogen) and poison gas (fluorine, chlorine).

To follow up, I asked them several questions:

- Where are the metals in the periodic table?

- Where are the non-metals?

- Where are the inert gasses? What do you notice in particular with respect to their distribution?

- Why inert gasses are arranged in a column?

- Are there any other groups whose elements are distributed in the same column?

- Could it be that the elements in the same column have the same properties? Why?

At this point, the debate resembled an informal lecture where the teacher leads the discussion by asking questions and providing information. Gradually, the concept of the family of elements emerged as a set of elements that have common properties. The film on chemical families was introduced the next day by another teacher, to reinforce learning by allowing students to compare their efforts with those of scientists (Monk \& Osborne, 1997). 


\section{Discussion}

The first strategy unfolded very well. The students worked enthusiastically and found very pertinent categories. However, I pointed out some wavering at the beginning of the group activity as several students told me they did not know what to do. As such, the students would have needed more time in the introduction to be better prepared to the activities. For example, I should had asked more questions to help them in the categorization process. I should also worked more with students on how to associate elements with their properties and initiate the activity of classification with the whole class by showing them an example of how to group several elements together. The students participated well during the analysis of regroupings obtained by each team. They made several suggestions and interesting criticisms. As a teacher, I would have liked that the students made more links between properties and tried to generalize their results so that they could generate more hypotheses. I had my part of responsibility in that outcome. I should have envisaged more general questions such as: "Is there a way to gather what you have just said in a single sentence?" or "Can you generalize what you have just said to other groupings?" It was very difficult for me to envisage incentive questions because I did not have any idea a priori of the way they were going to approach the subject.

At first, I should have made them work only with lists they had worked out themselves. I should have given them the list of known properties of elements only after the classification process had been well engaged, as a way of supporting their step. Moreover, to save valuable time, the deck of cards should have already been completed before giving it to the students at the beginning of the activity. In the same vein, I also pointed out previously that the students did not record their step in writing. I think that the principal cause of this situation was the set of cards given at the beginning of activity. Finally, to make them write their step, the cards should have been given to students only during the second strategy and only as a way to allow them to prove their hypotheses faster.

I perhaps too much tried to guide them, by giving them suggestions of approach. As such, teachers need to be careful to exert as least influence they could on students' process of categorization of the student. Indeed observing this process may reveal teachers the way their students think (J oyce \&Weil, 2004). I already pointed out before that the students who had not been helped were much more creative, and it is much easier for the students to generate hypotheses from their regroupings. Indeed, the different categories created by students should be commented by other students or teacher only when students have the opportunity to reflect on their strategies and analyze them. This oppportunity is most likely to happen when students return to whole class discussions. One bit of advice is to trust more the capacities of students and let the approach unfold as planned without interrupting it. Let it go a little more go even if it seems to take a bit strange turn. It is perhaps in this time that interesting things take place. 


\section{Conclusion}

Our results point out that the sequence engages students in developing their classifications as well as find arguments to test them as they discuss their ideas in small groups and later expose them to classroom discussion. We discussed previously conditions of implementation, such as the importance of providing a way to register all the contributions of each team to help sharing and examining the various hypotheses. One key aspect concerns the ability of the teacher to find the proper balance between supporting students' process of categorization while not interfering with it.

To improve the learning sequence, we first suggest to use in the first part a tablet of large paper sheets and a marker in each team. This provision would help students note their respective contributions (Brown \& Campione, 1990). It would also allow collective work in small groups to be more easily discussed upon by students in plenary. If the blackboard is not big enough to register all contributions, it would bethen possible to glue the paper sheets together to walls. At first, it would be wise for the teacher not to add elements to the list made by students. Only when the classification process has been launched, should the teacher's list of elements and their properties could be distributed to students and act only as support of their step only.

The set of cards should already contain all pertinent information on the characteristic properties of every element so that students would not waste time copying out information. Teacher should distribute the cards during the second strategy to allow the students to prove their hypotheses faster. We included more elements that the number covered in high school that usually stops at the atomic number of 20 . This recommendation follow the key strategies used by Mendeleev in building the periodic elements with the notion of elements, the notion of atomic mass and the notion of chemical properties (Scerri, 2011). Moreover, incentive questions that correspond to students' intellectual level should be conceived at all stages of the process. When beginning the third strategy, it is possible to regroup these questions in the form of a cognitive map (Hyerle \& Alper, 2011).

Finally, we could say that the inductive model used here is one of the rare who, starting from their initial knowledge, leads students progressively to formulate hypotheses, test them and apply them to other situations. However, to succeed in accomplishing these objectives, the students should possess a solid base of information. Information about properties of elements could be provided during preparative activities such as laboratory experiments, research work on elements with the Internet, etc. Morevoer, teachers should plan activities so students can test their hypotheses concretely. This recommandation may prevent students completing the activity with the comment: "O.K., we enjoyed it, nowlet us pass to the serious things!" I remember a student who made me following remark: "It is very nice to enunciate hypotheses, but what do we do with it?" Preparation activities and some resources easily available are required to help students in the process. Fortunately, opportunities are greater than ever with the advent of information and communication technologies (ICT). Using ICT, students can access databases at the click of a mouse, make experiments online, etc. 
However, students still require guidance from their teacher and input from their peers to help them in the process of constructing new chemical concepts. Teachers could use the activities proposed here for various purposes. For example, they could use these activities to introduce their students to the periodic table. Their students would then be given a sense of the nature of science by following the steps of the founders of one of the overarching principle of modern chemistry. 


\section{References}

Aldersey-Williams, H. (2011). Periodic tales: A cultural history of the elements, from arsenic to zinc. New York: HarperCollins Publishers.

Baylor, G.W. (2001). What do we really know about Mendeleev's dream of the Periodic Table? A note on dreams of scientific problem solving. Dreaming, 11(2), 89-92.

Barrett, D.(2001). A note about dreams of scientific problem solving. Dreaming, 11(2), 93-95.

Ben-Zvi, N. \& Genut, S. (2007). Uses and limitations of scientific models: the Periodic Table as an inductive tool. International J ournal of Science Education, 20 (3), 351-360.

Altrichter, H., \& Hollly, M.L. (2005). Research Diaries. In Somekh, B., \&C. Lewin, C. (Eds), Research Methods in the Social Sciences, chap. 2, p. 24-32. Thousand Oaks (CA) : SAGE.

Brito, A., Rodriguez, M.A., Niaz, M. (2005). A reconstruction of the development of the periodic table based on history and philosophy of science and its implications for general chemistry textbooks. J ournal of Research in Science Teaching, 42(1), 84-111.

Emsley, J . (2011). Nature's building blocks: Everything you need to know about the elements, new edition. Oxford: Oxford University Press.

Gordin, M.D. (2005). A well-ordered thing: Dimitri Mendeleev and the shadow of the periodic table. New York: Basic Books.

Hyerle, D.N., \&Alper, L. (2011). Student successes with thinking maps: School-based research, results, and models for the achievement using visual tools. Thousand Oaks (CA): Corwin.

J oyce, B., Weil, M., Calhoun, E. (2004). Models of teaching, 7th ed. Montreal: Pearson Education.

Krebs, R.E. (2006). The history and use of our earth's chemical elements: A reference guide, $2^{\text {nd }} \mathrm{ed}$. Westport (Connecticut): Greenwood Press.

Martinand, J .L. (1986). Connaître et transformer la matière. New York: Peter Lang.

Monk, M. \& et Osborne, J . (1997). Placing the history and philosophy of science on the curriculum: A model for the development of pedagogy. Science Education, 81, 405-424.

Moon, J .A. (2006). A handbook for reflective practice and professional development, $2^{\text {nd }}$ ed. New York: Routledge.

Moxley, J .A. (2007). Graphing in the classroom for improving instruction: From lessons plans to research. Education and Treatment of Children, 30(2), 11-126

Scerri, E. (2011). Le tableau périodique: Son histoire et sa signification. France: EDP Sciences.

Taba, H. (1971). A teacher's handbook to elementary social studies: An inductive approach, $2^{\text {nd }} \mathrm{ed}$. Reading (MA): Addison-Wesley. 